\title{
Masculinidades na Educação Física escolar: um estudo sobre os processos de inclusão/exclusão
}

CDD. 20.ed. 796.017

796.5

\author{
Leandro Teófilo de BRITO* \\ Mônica Pereira dos SANTOS*
}

\section{Resumo}

Este estudo de caso teve como objetivo identificar os processos de inclusão/exclusão, em uma turma masculina de Educação Física escolar do ensino fundamental. Inclusão/exclusão, neste trabalho, são termos entendidos em uma relação dialética, um fenômeno compreendido sob uma característica dinâmica e indissociável, onde não se pode considerá-los através de significados distintos. Constatamos através da observação participante, com anotações em diário de campo, que o mecanismo central de inclusão/ exclusão esteve baseado no desempenho físico e motor para a prática esportiva, em conjunto com uma competitividade exacerbada, caracteristica central do modelo hegemônico de masculinidade, que se fez predominante entre os meninos nas aulas. Reconhecemos que a prática pedagógica do(a) professor(a) pode influenciar as interações entre os sujeitos, durante as atividades corporais, permitindo o convivio harmonioso de formas múltiplas de masculinidades entre os alunos, em direção ao movimento pela inclusão nas aulas de Educação Física e na Educação, de uma maneira geral.

Palavras-chave: Gênero: Educação; Esporte.

\section{Introdução}

Diversas pesquisas mostram que os estudos de gênero na Educação Física têm investigado, dentre outros temas, questões relacionadas às resistências culturais sobre a participação efetiva das meninas nas aulas mistas de Educação Física escolar ${ }^{1-5}$. As pesquisas, de uma forma geral, apontam para a diferença de desempenho motor das meninas nos esportes, como o grande problema enfrentado pelas mesmas nas aulas conjuntas com os meninos, gerando situações de exclusão. Em pesquisa com turmas femininas de Educação Física no ensino médio, Devide et al. ${ }^{6}$ identificaram que a habilidade motora, assim como nas aulas mistas, também se apresenta como o principal critério de exclusão entre as meninas nas aulas. Os autores intitularam esta forma de prática social como: "exclusão intrassexo" (p.87).

Em paralelo a estas investigações encontram-se em desenvolvimento recente, os estudos acadêmicos nacionais que trazem como foco a construção de identidades masculinas por meio de práticas corporais e esportivas, analisados através dos referenciais teóricos de gênero ${ }^{7-13}$. Fazendo parte deste mesmo campo de estudos, ainda são poucas as investigações que abordam especificamente a construçáo de masculinidades por meio da Educação Física escolar ${ }^{14-20}$.

Inclusão/exclusão, neste trabalho, são termos entendidos em uma relação dialética, um fenômeno compreendido sob uma característica dinâmica e indissociável, onde não se pode considerá-los através de significados distintos ${ }^{21-22}$. Considerando estas afirmaçōes, esta pesquisa apresenta como problema a seguinte questão: Como os processos de inclusão/ exclusão se fazem presentes nas aulas de uma turma masculina de Educação Física escolar do ensino fundamental? O objetivo central desta pesquisa foi investigar nas práticas corporais escolares, em específico numa turma masculina de Educação Física, como os mecanismos de inclusão/exclusão se manifestam, identificando seus critérios e traçando um paralelo com os estudos existentes sobre aulas mistas e turmas femininas. Justifica-se a presente pesquisa, pois se faz necessária a contribuição de dados aos estudos de gênero, frente às questóes de inclusão/exclusão nas aulas de Educação Física 
compostas por alunos do mesmo sexo, em específico neste trabalho com uma turma masculina; além de compreender aspectos gerais relacionados aos processos de inclusão/exclusão presentes em diferentes contextos do cotidiano escolar.

A seguir apresentaremos à compreensão de inclusão, com a qual este trabalho se pauta, logo após discutiremos o conceito de gênero e as representaçõos de masculinidades em associação à Educação Física e à prática dos esportes. $\mathrm{Na}$ sequência serão apresentados dados da pesquisa de campo, realizada no cotidiano de aulas masculinas de Educação Física de uma escola pública, e por fim nossas considerações finais sobre a pesquisa.

\section{Inclusão/exclusão em educação}

Um dos maiores desafios da escola no nosso presente, a educação básica de qualidade por meio da inclusão escolar, onde o respeito pelas diferenças de gênero, orientação sexual, raça, etnia, etc. deve ser garantido e colocado em prática, tem se configurado como uma das grandes buscas desse nosso século. SANTOS ${ }^{22}$ afirma que o termo inclusão, muitas vezes direcionado a ações para a educação especial ou confundido com a integração de pessoas com deficiências, está inserido em um contexto mais amplo, devendo ser compreendido como um processo, reiterando princípios democráticos de participação social plena, e visto como uma luta em todas as áreas da vida humana. O conceito de inclusão é esclarecido pela referida autora:

[...] o processo de inclusão se refere a quaisquer lutas, nos diferentes campos sociais, contra a exclusão de pessoas: tanto as que se percebem com facilidade, como aquelas mais sutis. Refere-se ainda, num nível mais preventivo, a todo e qualquer esforço para se evitar que grupos e sujeitos em risco de serem excluídos de dados contextos, por qualquer motivo que seja, acabem sendo excluídos de fato (p.12).

Discutir inclusão significa automaticamente discutir também a exclusão. Santos e Paulino ${ }^{21}$ complementam esta questão:

$\mathrm{O}$ processo de exclusão anela-se ao da inclusão pelo caráter de dimensões (desigualdade, inadaptação, injustiça social e exploração social) e a não necessidade de precisão de conceitos entre um $\mathrm{e}$ outro, pois tais fatores apresentados nos remetem a identificar um e propor o outro. Seus reflexos perante a sociedade nos remetem à visualização de um grande movimento social (p.18-19).

Três dimensões estão associadas aos processos de inclusão/exclusão, com base nos estudos de ВоOTH e Ainscow ${ }^{23}$, Santos e Paulino ${ }^{21}$ e Santos $22: a$ criação de culturas, o desenvolvimento de políticas e a orquestração de práticas de inclusãolexclusão. A criação de culturas engloba os princípios, valores, percepções e conceitos que internamente construímos em nossas práticas discursivas e em nossas crenças, legitimando nossas intenções e ações. $\mathrm{O}$ desenvolvimento de políticas é explicitado nas estratégias institucionais (em âmbito micro, meso ou macro), como documentos, projetos político-pedagógicos, planejamento de aulas ou até mesmo nas regras e acordos disciplinares que ocorrem nas salas de aula. A orquestração de práticas se refere às açōes no cotidiano educacional, através do fazer pedagógico, didático, avaliativo, ético, gestor, etc. É a dimensão que coloca os princípios (culturas) e estratégias (políticas) em ação através das práticas de inclusão/exclusão no contexto educacional. Esta é a chamada tridimensionalidade dos processos de inclusão/exclusão.

SANTOS ${ }^{22}$ complementa afirmando que a estrutura das dimensões culturas, politicas e práticas de inclusãolexclusão encontra-se presente em qualquer instituição, de qualquer nível educacional, ou mesmo em qualquer sistema ou organização. A autora vem atualmente intitulando esta perspectiva de educação como omnilética ${ }^{24}$, incorporando estas três dimensōes para análise e explicação da dialética, além da complexidade na relação dos processos de inclusão/exclusão. Pensar omniléticamente e em educação consiste em adotar, simultaneamente, as perspectivas dialética materialista ${ }^{25}$, complexa ${ }^{26} \mathrm{e}$ tridimensional de análise ${ }^{21-23}$ sobre os eventos educacionais, considerados também sociais, culturais, históricos, políticos, econômicos, etc.

Dando continuidade à discussão, nos debruçaremos na explanação do conceito de gênero. 


\section{Sobre o conceito de gênero}

Para BouRdieu ${ }^{27}$ o simbolismo das diferenças entre os corpos masculino e feminino, com ênfase na diferença anatômica dos órgãos sexuais, em outras palavras a diferença biológica entre os sexos, tornase a justificativa natural da diferença socialmente construída entre os gêneros, sobrepondo masculino ao feminino.

SiLVA $^{28}$ afirma que o biólogo americano John Money, em 1955, foi um dos pioneiros na utilização da palavra "gender", objetivando discutir os aspectos sociais do sexo. Anteriormente, gênero era uma palavra apenas restrita à gramática, com o objetivo de explicitar o sexo dos substantivos ou nomear as formas masculinas e femininas na linguagem.

SCOTT $^{29}$ aponta que a utilização do termo gênero objetivou designar as relaçôes sociais entre os sexos, ou seja, uma forma de se referir às origens exclusivamente sociais das identidades subjetivas de homens e mulheres, identificadas como masculinas e femininas. A autora também levanta que o termo, durante um determinado tempo, foi sinônimo de "mulheres", principalmente nos trabalhos de cunho acadêmico, que visavam um maior reconhecimento político e certa aproximação com os estudos das ciências sociais:
Na sua utilização recente mais simples, "gênero" é sinônimo de "mulheres". Os livros e artigos de todos os tipos que tinham como tema a história das mulheres substituíram, nos últimos anos, nos seus títulos o termo "mulheres" por "gênero". [...] Esse uso do termo "gênero" constitui um dos aspectos daquilo que se poderia chamar de busca de legitimidade acadêmica para os estudos feministas dos anos $80 .{ }^{29}$ (p.75).

Os estudos de gênero não estão mais associados única e exclusivamente às mulheres, e referem-se também a questôes sobre os homens e a construção de masculinidades, embora permaneçam apoiados em referências dos estudos feministas. Esta compreensão tem levado a um aumento significativo de estudos que possuem como foco as representaçóes de masculinidades, mostrando que as questôes de gênero possuem implicações não só epistemológicas, mas relacionadas também com problemas e preocupações vitais para o mundo e a época em que nos situamos ${ }^{28}$.

Abordaremos na sequência as interlocuções existentes entre masculinidades e Educação Física, discutindo os estudos desenvolvidos por ConNELL ${ }^{30-31}$ e alguns autores que tratam do tema gênero, masculinidades, práticas corporais e esportes.

\section{Masculinidades e Educação Física}

ConNELL ${ }^{30}$ conceitua a masculinidade como: “[...] uma configuração de prática em torno da posição dos homens na estrutura das relações de gênero" (p.188). A construção da masculinidade se faz em oposição à feminilidade e aos aspectos que são associados a ela, em especial o modelo hegemônico de masculinidade que se contrapõe não só ao feminino, mas também a outras formas de masculinidades. Para ConNELL ${ }^{30}$ existe uma narrativa convencional sobre como as masculinidades são construídas, e nessa narrativa toda a cultura possui um direcionamento de conduta e sentimentos que todo homem deve seguir, existindo uma pressão nas ações para um afastamento do feminino, compreendido sempre como oposto, advindos das famílias, das escolas, dos colegas, etc. Entretanto essa narrativa encontra-se incompleta, embora não esteja errada totalmente, pois ela adota apenas uma forma de masculinidade para definir a masculinidade no geral, ela também reconhece as personalidades masculinas como se estivessem numa fábrica, sendo produzidas em modelos iguais, na ponta de uma esteira, além de não reconhecer a construção das masculinidades tanto como um projeto coletivo e como um projeto individual: "Se as masculinidades são construídas através dessas formas, elas são também constantemente reconstruídas" ${ }^{30}$ (p.191).

Diferentes masculinidades são produzidas em um mesmo contexto social. Dentre estas masculinidades, a sua forma hegemônica - masculinidade hegemônica - possui outras masculinidades agrupadas ao seu redor. Levando-se em consideração a cultura ocidental, os outros modelos de masculinidades propostos pela autora, agrupados à masculinidade hegemônica são: subordinada, cumplice e marginalizada ${ }^{31}$. Explicitaremos assim cada uma delas.

A masculinidade hegemônica é aquela ligada a legitimação do patriarcado ${ }^{b}$. Refere-se à dinâmica cultural pela qual um grupo exige e mantém uma posição de liderança na vida social, possuindo estreita ligação com a posição dominante dos homens, 
exclusão de outras formas de masculinidades e submissão das mulheres. ConNELL ${ }^{30}$ nos lembra que a masculinidade hegemônica estará sempre sujeita à contestação e à transformação ao longo do tempo.

A masculinidade subordinada se refere à dominância e subordinação entre grupos de homens, mais especificamente à dominação de homens heterossexuais e à subordinação de homens homossexuais. Entretanto a autora também aponta outras formas de masculinidades subordinadas: "La masculinidade gay es la más conspícua, aunque no es la única masculinidade subordinada. El círculo de legitimidade también expulsa a algunos hombres y niños heterosexuales"31 (p.119).

A masculinidade cúmplice diz respeito a uma ligação existente com o projeto de masculinidade hegemônica, onde alguns homens desfrutam das vantagens do patriarcado, sem assumirem tal fato. Diz respeito a uma cumplicidade com a masculinidade hegemônica e suas benesses: "[...] la mayoría de los hombres ganan com esta hegemonia, ya que se benefician de los dividendos del patriarcado; em general, el hombre obtiene ventajas de la subordinación general de las mujeres"31 (p.119-20).

E por fim a masculinidade marginalizada, que é aquela associada a grupos étnicos minoritários e divisão de classes de grupos explorados ou oprimidos, que se encontram marginalizados na sociedade, excluídos sob a condição de classe ou raça. As masculinidades negras podem ser consideradas exemplos da masculinidade marginalizada ${ }^{31}$.

Qualquer forma particular de masculinidade pode ser considerada complexa e até mesmo contraditória, conforme sinaliza CoNNELL ${ }^{30}$ :

$\mathrm{O}$ fato da contradição faz com que seja essencial ter uma definição de masculinidade que não equacione gênero simplesmente com uma categoria de pessoas. Se a "masculinidade" significasse simplesmente as características dos homens, não poderíamos falar da feminilidade nos homens ou da masculinidade nas mulheres (exceto como desvio) e deixaríamos de compreender a dinâmica do gênero (p.189).

Neste contexto a Educação Física escolar por meio de suas práticas corporais, com destaque para o esporte, legitimado como área masculina reservada ${ }^{32}$, mantém forte ligação com a masculinidade hegemônica. De acordo com KnIJNIK e FALCÃo-Defino ${ }^{12}$ :

O esporte, nesse contexto, joga um papel preponderante na constituição das masculinidades, pois está na rotina das pessoas, funcionando como um perfeito panóptico que constantemente vigia as diversas expressōes de masculinidades individuais e coletivas, que nele são produzidas e reproduzidas, proporcionado prazeres e emoçōes exagerados e benefícios psicológicos ao ego masculino (p.177-8).

OliveirA $^{33}$ destaca a estreita relação de valores ditos masculinos com a prática dos esportes, em específico no exemplo da ginástica, no início do século XVIII. Segundo o autor, a ginástica era um meio de se atingir força e vigor de forma disciplinada, sendo submetida constantemente aos meninos como parte da formação de um ideal de masculinidade e virilidade, objetivando torná-los saudáveis, robustos e possuidores de sapiência e sensatez. Segundo o autor:

Pela via dos esportes a masculinidade se estendia por todo o corpo social enquanto valor e símbolo consagrado, ultrapassando barreiras de classe, religião e todas as outras diferenças que poderiam limitar a hegemonia e homogeneidade de sua valorização. [...] Aguentar as provaçôes da vida diária e se manter firme era um lema presente em muitos manuais de ginástica e em narrativas do período que serviam de forma direta para estimular o exercício e o treinamento físico (p.63).

Para Vieira 4 , a atividade esportiva nas aulas de Educação Física assume um rito de passagem para meninos tornarem-se homens, por meio da incorporação de papéis sociais de masculinidade e virilidade, impostos culturalmente pela prática dos esportes. Desta forma para o autor o esporte costuma a ser visto socialmente como um espaço no qual o indivíduo desenvolve sua independência, sua força física, sua agressividade e a capacidade de disputa, sendo todas características que a sociedade culturalmente atribui aos homens.

PAECHTER $^{34}$ afirma que a Educação Física e o esporte escolar contribuem para a construção de identidades masculinas, onde vigor, força física e boa forma corporal classificam-se como valores simbólicos que representam culturalmente o que é ser homem. A autora aponta que meninos que se mostram resistentes à sua prática nas escolas, acabam sendo excluídos de comunidades de masculinidades dominantes e hegemônicas, configurando-se desta forma uma obrigação do sexo masculino em internalizar o esporte como um dever na sua formação.

Segundo CaValeiro e Vianna ${ }^{17}$ :

O esporte é visto, assim, como parte da existência masculina. Essas conexôes são perceptíveis em nossa sociedade e na escola: gostar de futebol ou de exercícios físicos pesados, jogar duro, mostrar-se rude e desprezar a dor, isto é, jogar sem se importar em ser ferido é considerado quase uma "obrigação" para qualquer menino ou garoto "normal e sadio (p.140). 
O papel que o esporte assume em nossa sociedade, constrói, forja e educa a masculinidade hegemônica deixando sequelas nos variados contextos esportivos, fato que é facilmente observado nas aulas de Educação Física escolar. Exemplo disto é a grande dificuldade que homens e mulheres, meninos e meninas têm de praticar esportes em conjunto ${ }^{12}$.

Apresentamos na sequência as escolhas metodológicas que direcionaram nossa pesquisa de campo, no cotidiano das aulas de Educação Física em uma escola pública.

\section{Método}

Classificando-se como um estudo de caso ${ }^{35}$, esta pesquisa de campo ocorreu em uma escola da rede municipal da cidade de Nova Iguaçu, localizada na região da baixada fluminense, Estado do Rio de Janeiro. Segundo YIN ${ }^{35}$ o estudo de caso como método de pesquisa é usado em muitas situações para contribuir ao nosso conhecimento dos fenômenos individuais, grupais, organizacionais, sociais, políticos e relacionados, permitindo que os investigadores retenham as características holísticas e significativas dos eventos da vida real, como por exemplo, o desempenho escolar e o comportamento de pequenos grupos.

Buscou-se para esta pesquisa uma escola onde as aulas de Educação Física são separadas por sexo ${ }^{c}$. Uma turma masculina, composta aproximadamente de 25 alunos do $4^{\circ}$ e $5^{\circ}$ anos do ensino fundamental, com idades entre nove e 12 anos foi escolhida para a investigação. Sobre a coleta de dados, que ocorreu entre os meses de maio e julho de 2011, totalizando 10 aulas de 50 minutos, utilizou-se a técnica da observação participante:

$\mathrm{Na}$ observação participante, o pesquisador (a) deve interagir com o contexto pesquisado, ou seja, deve estabelecer uma relação direta com os grupos ou pessoas, acompanhando-os em situaçôes informais ou formais e interrogando-os sobre os atos e seus significados por meio de um constante diálogo ${ }^{36}$ (p.81).

O tipo de observação participante utilizada nesta investigação é a observação artificial, que é aquela em que o pesquisador se integra ao grupo com o objetivo de fazer pesquisa, diferenciando-se da observação natural, onde o pesquisador é parte integrante do grupo $^{36}$. As observações tiveram o cuidado de ser transcritas em um diário de campo no decorrer das aulas, e revisadas ao término das mesmas.

Os dados desta pesquisa são oriundos de uma dissertação de mestrado em andamento, não sendo exigido pela banca examinadora e pela universidade a submissão do estudo ao comitê de ética em pesquisa, tendo em vista a permissão da Secretaria Municipal de Educação da cidade de Nova Iguaçu para a realização da pesquisa na escola. A professora e os responsáveis pelos alunos assinaram um termo de consentimento livre e esclarecido, concordando com a apresentação dos dados em publicação, sendo esclarecidos da não existência de riscos e da possibilidade de desistirem da pesquisa a qualquer momento. Os nomes apresentados na pesquisa são fictícios, preservando desta forma o anonimato dos participantes.

Os dados coletados na observação participante, através do diário de campo, foram interpretados através da análise de conteúdo ${ }^{37}$. Considerada uma metodologia de análise de dados de grande importância na área da comunicação, a análise de conteúdo pode ser definida como: "[...] um conjunto de técnicas de análises das comunicaçōes que utiliza procedimentos sistemáticos e objetivos de descrição do conteúdo das mensagens" ${ }^{\prime \prime 7}$ (p.44). A intenção da análise de conteúdo é a inferência, que recorre a indicadores quantitativos ou não, de conhecimentos relativos às condições de produçãa/recepção das mensagens. Estes dados obtidos serão discutidos com base nos referenciais da teoria de gênero - com ênfase nos pressupostos dos estudos sobre masculinidades - e nos estudos sobre inclusão/exclusão.

\section{Resultados e discussão}

Os dados apresentados para discussão serão excertos retirados do diário de campo, com recuo do parágrafo e identificados com as datas das aulas que foram observadas. Apresentaremos então algumas situações cotidianas de uma turma masculina de
Educação Física e como os processos de inclusão/ exclusão atravessaram as aulas:

A exclusão que se fez presente na competitividade

O Futebol era o conteúdo trabalhado em aula. Os alunos chegaram ao campo de Futebol, local onde 
ocorriam as aulas, com dois times praticamente definidos. Alguns alunos estavam sem times e indagaram à professora que os dois times formados eram "fortes" demais, solicitando o seu auxílio para mesclá-los. A professora tentou intervir propondo uma nova divisão das equipes, mas a resistência foi muito grande e ela deixou os grupos divididos como estavam, ou seja, dois times "fortes", que se formaram inicialmente e o outro mais "fraco" com os alunos que chegaram à aula sem times (Diário de Campo, 1ª aula, 02/05/2011).

A atitude excludente dos alunos, aliada a uma competitividade até certo ponto exacerbada, mostrase como viés inicial de análise da aula observada. Para os alunos os jogos de Futebol poderiam ocorrer com o confronto das duas equipes, classificadas por eles como "fortes", excluindo de participação os alunos denominados de "fracos". SANTOS ${ }^{22}$ afirma que toda a prática que segregue indivíduos, desconsiderando os diferentes aspectos identitários de cada um, seja em um determinado grupo ou em algum contexto social, gerando desconforto e constrangimento, deve ser evitada. Sobre a competitividade, AltmanN ${ }^{38}$ afirma que: "[...] a competitividade presente na prática esportiva na escola - um dos valores do chamado esporte moderno - tem sido um fator de exclusão nas aulas de Educação Física” (p.52).

A competitividade, característica visível entre os meninos na aula, mostra-se como uma construção cultural de gestos e atitudes típicas do comportamento masculino, na constituição de suas identidades sociais. KNIJNIK e FALCÃO-DEFINO ${ }^{12}$ relatam que apesar das diversas evoluções, sejam elas tecnológicas, políticas ou sociais, as normas de gênero hegemônicas continuam se sobrepondo nas relações de poder, criando no esporte um ambiente além de competitivo, excludente e violento. Cavaleiro e Vianna ${ }^{17}$ afirmam que o desenvolvimento da competição aliado a valores como força, coragem e autocontrole, são pontos de apoio para a disseminação dos ideais viris da modernidade, típicos da masculinidade hegemônica.

Segundo PAeChter ${ }^{34}$ :

Nas comunidades de prática de masculinidade que se desenvolvem no âmbito da educação física escolar, a identidade passa a ser associada à competência nos esportes, o que demonstra pertencimento e posiçōes poderosas dentro da comunidade. [...]. Sob esse ângulo a educação física e os esportes escolares não somente ensinam formas determinadas de ser um homem, mas também induzem os meninos a integrarem uma comunidade ampla de práticas de masculinidade nas quais, em virtude de sua performance relativa, alguns são dominantes e outros subordinados [...] (p.137).
Outra questão que se traz para discussão está relacionada à postura da professora em não intervir, devido às reclamações dos alunos, nos grupos divididos para os jogos de Futebol. A professora ao manter os grupos divididos como chegaram à aula, omitiu-se de uma intervenção, que pelo menos minimizasse a exclusão instaurada durante a prática do jogo de Futebol.

Nos dias de hoje as desigualdades sociais e o desrespeito às diferenças são banalizados em nosso cotidiano, e a escola, sem dúvida, reflete e reproduz estas relações. Desta forma, nossa sociedade e, por conseguinte, nossa escola, está envolvida por uma lógica que determina a exclusão de alguns grupos para o beneficiamento de outros, em detrimento de valores igualitários expressos em diversas declarações mundiais como a Declaração Universal dos Direitos Humanos, por exemplo ${ }^{21}$ (p.11).

\section{O confronto de masculinidades na aula}

Ainda na primeira aula pudemos identificar os líderes da turma: dois alunos com características físicas distintas, que figuravam entre os comandantes dos times de Futebol, denominados de Alan e Pedro'. Alan era mais alto, aparentando mais idade que os demais e bastante habilidoso. Pedro não possuía muita habilidade, sendo visivelmente obeso, mas que exercia um grande domínio frente aos outros meninos através de uma certa postura de "intimidação". Era visível que os outros meninos tinham um certo "medo" dele. Cada um deles pertencia a uma das equipes mais fortes. Nas observaçôes dos jogos em que o Pedro esteve presente, constatei que o mesmo participava bem pouco do jogo, devido a sua forma física não permitir que ele corresse por todo o espaço do jogo, além da dificuldade no domínio das habilidades básicas do Futebol, como chutar e driblar. No confronto com a equipe "mais fraca”, que foi derrotada nos dois jogos, Pedro foi o primeiro a incitar algumas provocaçōes, referindo-se aos alunos através de termos pejorativos como "perdedores e ruins de bola”. Ao final da aula a professora reuniu todos da turma, repreendendo a atitude de Pedro ao afirmar não admitir mais esse tipo de conduta dele e de nenhum outro aluno nas aulas subsequentes.

Cavaleiro e Vianna ${ }^{17}$ relatam que agressões e insultos, decorrentes das cobranças de atitudes e posturas corporais, como estas que foram descritas no relato da aula, são identificadas como própria de um homem na esfera social, corroborando com características pertencentes à masculinidade hegemônica. No caso específico de Pedro, este escondia a visibilidade na sua inabilidade motora para o Futebol, fazendo parte de um grupo onde havia meninos habilidosos, 
e desmerecendo através de piadas e deboches aqueles alunos que perdiam nos confrontos entre as equipes. Pereira ${ }^{8}$ relata que: "O ser masculino não está acostumado a lidar com os sentimentos. Escamoteia e parte para uma agressão sustentada pelo contexto cultural, social e histórico" (p.97). Complementando a questão, MORAES E SILVA e CÉSAR ${ }^{18}$, afirmam que: Os xingamentos utilizados pelos meninos nas aulas de Educação Física acabam por ilustrar essas questôes, pois se dirigem aos considerados "afeminados" e aqueles com um desempenho motor e físico inferior, ou seja, tais falas visam realizar uma dominação simbólica sobre os meninos que não cumprem a economia política do gênero (p.171).

ConNelL ${ }^{30}$ aponta que novas formas de masculinidades estão configurando-se na busca de uma masculinidade mais racional e melhor ajustada, embora ainda contestadas pela masculinidade hegemônica, que tem o impulso e a violência como valores determinantes. Alguns grupos de homens, segundo a autora, pagam o preço de uma ordem de gênero não igualitária, por não se apresentarem dentro de um padrão convencional de masculinidade. Podemos fazer uma associação desta afirmação com este relato da aula, onde os meninos da equipe que é derrotada são subjugados, sendo ofendidos por não se apresentarem dentro de um modelo pré-concebido para a prática do esporte. Para Louro 39 : “[...] aqueles homens que se afastam da forma de masculinidade hegemônica são considerados diferentes, são representados como o outro e, usualmente, experimentam práticas de discriminação ou subordinação" (p.48). BOURDIEU $^{27}$ afirma que os homens, assim como as mulheres oprimidas pela dominação masculina, são vítimas e prisioneiros também de sua própria representação dominante de um ideal cultural de virilidade. De acordo com KNIJNIK e FALCÃO-DeFINO ${ }^{12}$ :

Parece que estamos vivendo um momento de transição e de grande confusão da própria identidade masculina, pois as relaçōes de gênero nunca estiveram tão confusas. Ser homem atualmente é uma tarefa árdua, pelas complexidades e contradiçōes existentes na própria constituição da masculinidade (p.181).

SANTOS $^{22}$ afirma que as construções de exclusão no ambiente escolar são justamente os preconceitos construídos pelo estranhamento, algumas vezes excessivo, das diferenças que compõem a diversidade dos alunos. $\mathrm{O}$ trato com a diversidade deve estar presente em todos os setores das relaçóes humanas, não se abstendo da educação escolar. As dimensões culturas e politicas de inclusãolexclusão foram explicitadas na fala da professora, quando a mesma afirma não admitir mais nas aulas de Educação Física provocações aos alunos que por ventura vierem a perder no jogo de Futebol. Para SANTOS ${ }^{22}$ as culturas de inclusão estão relacionadas aos valores construídos em nossas práticas discursivas, nas justificativas, nas crenças e em tudo aquilo que legitimará nossas políticas/ intençōes e ações. As políticas de inclusão por sua vez são identificadas pela expressão dessas intençôes, através das condutas exigidas pela professora em aula.

\section{A exclusão como resposta}

Durante a aula uma das equipes por ter ganhado o primeiro jogo, propôs à professora que eles ficassem em campo até que perdessem um jogo, revezando as outras duas equipes formadas, sempre em confronto com eles. A professora aceitou a proposta, afirmando aos alunos que em algum momento eles seriam derrotados cedendo a vez às equipes de fora. A derrota dessa equipe não ocorreu durante grande parte da aula. Faltando 10 minutos para o encerramento, a professora pediu que esta equipe se retirasse do campo, propondo um confronto entre as duas equipes que se revezavam. O grupo não aceitou retirar-se do campo, e em resposta à situação a professora decidiu encerrar a aula naquele momento. De acordo com a professora a turma inteira seria penalizada com duas aulas sem Futebol (Diário de Campo, 4a aula, 13/06/2011).

$\mathrm{Na}$ análise deste relato, compreende-se que o objetivo inicial da professora seria promover a inclusão dos alunos que jogavam relativamente menos na aula, tendo em vista uma exclusão que já vinha ocorrendo na prática do Futebol durante as aulas. A resistência dos alunos que venciam os jogos, através da atitude de não deixar o campo para a entrada das outras equipes, culminou com a punição de toda a turma, gerando uma exclusão generalizada com duas aulas sem jogos de Futebol. Para SANTOS ${ }^{22}$ : "as exclusões são muito mais uma construção social do que um dado natural [...]” (p.13). Neste caso específico para manter uma posição de autoridade perante um grupo indisciplinado, uma certa postura que é cobrada socialmente do docente, a professora utilizou-se de sua posição nas relações de poder ao reprimir a atitude dos alunos, ocasionando assim a exclusão mencionada. Inclusão e exclusão possuem variadas facetas, conforme se constata no relato da aula. Como são conceitos compreendidos em relação dialética, acabam sendo repletos de contradiçôes, conflitos e tensões ${ }^{22}$.

Segundo Silva ${ }^{40}$ :

[...] a inclusão nas aulas de Educação Física tem como objetivo atentar primeiramente sobre o próprio papel da Educação Física, que não é da seleção de talentos atléticos, e de garantir a real participação de todos 
sem discriminação de nenhum tipo, na aquisição ou na produção de determinado conhecimento. [...]. Entretanto, esta não é uma tarefa fácil, pois requer intervenção permanente do professor (p.76).

AltmanN $^{38}$, em pesquisa sobre as relações de gênero no espaço escolar, afirma que de uma forma geral, os meninos transgridem mais as regras disciplinares que as meninas, como um meio de afirmação de uma masculinidade que é imposta socialmente, assim como ocorre com a prática do esporte. Conforme relata a pesquisadora, os principais casos de expulsão dos meninos nas aulas eram motivados por: “[...] gritaria, não realização de tarefas, desrespeito ao professor ou professora e brigas" (p.31).

\section{A inclusão que gerou exclusão}

Ao iniciar a aula, a professora utilizou uma estratégia em que os três meninos mais jovens da turma escolhessem as equipes para o jogo de Futebol. De uma forma geral, partindo das observações, os meninos mais novos da turma eram os mais excluídos da prática desportiva. Os jogos iniciaramse e Marcelo, um destes meninos mais jovens, após o primeiro jogo não ter tido uma participação efetiva, recebendo pouquíssimas bolas de passe dos companheiros, além de não ter conseguido realizar um chute ao gol, afirmou à professora: "tia, eu escolhi muito mal o time... deveria ter ficado num time mais fraco, pra pelo menos ter chances de jogar... só porque eles são maiores que eu, mais fortes também... fazem de conta que eu não sou também do time...”. A equipe de Marcelo obteve vitórias nos dois jogos disputados (Diário de Campo, 8ª aula, 04/07/2011).

Ao orquestrar uma prática de inclusão, propondo que a escolha das equipes ocorressem pelos alunos que eram excluídos constantemente nas aulas, a professora utilizou uma prática pedagógica que buscasse uma melhor participação desses alunos. SANTOS $^{22}$ esclarece a dimensão orquestrando práticas de inclusão: "refere-se ao fazer no cotidiano educacional. O fazer pedagógico, didático, avaliativo, ético, gestor [...]” (p.17). A sua intenção em promover a inclusão dentro do grupo - políticas de inclusão - foi explicitada e imediatamente colocada em prática através desta estratégia.

Nos contextos educacionais, há educandos que necessitam de procedimentos, recursos ou auxílios mais específicos para participarem mais ativamente das atividades propostas no ambiente educacional. [...] Os educadores têm uma responsabilidade em particular, em garantir que todos os educandos participem plenamente na sociedade e que tenham igualdade de oportunidades em educação ${ }^{22}$ (p.10-1).
Aprofundando uma análise omnilética deste excerto, percebe-se o quão escorregadio pode ser o terreno da inclusão. Metaforicamente, pode-se considerar o resultado desta iniciativa da professora como comparável à ideia de inclusão dentro da proposta de universalização do ensino: de fato, as portas da escola, nos últimos 20 anos, se abriram e as matrículas aumentaram na educação brasileira. No entanto, quantos alunos permanecem na escola e efetivamente aprendem? $\mathrm{Na}$ situação narrada: de fato, os que participavam menos tiveram uma chance de participar mais. No entanto, de que modo permaneceram no jogo e o quanto efetivamente jogaram/participaram? Que culturas em tensão prevaleceram, concomitantemente, no evento citado? Que práticas estiveram em jogo e que políticas poderiam gerar e a quais se remetiam?

Altmann" 38 afirma que um "emaranhado de exclusões" tais como gênero, idade, força e habilidade permeiam o contexto das aulas de Educação Física. Retomando o ocorrido nesta aula, Marcelo, além de ser um dos mais jovens da turma, era classificado como um dos menos habilidosos no jogo de Futebol. Marcelo escolheu a sua equipe com o objetivo de vencer os jogos. Conseguiu as vitórias, mas foi excluído pelos companheiros mais habilidosos no andamento das partidas, não conseguindo uma participação efetiva. A competitividade mais uma vez se fez presente, através de uma necessidade de autoafirmação de Marcelo, que talvez almejasse, através das vitórias nos jogos de Futebol, sobressair-se perante o grupo. Pereira e FERNANDES FILHO9 relatam que as diferenças de "status"o que geralmente a sociedade atribui para que um indivíduo do sexo masculino seja considerado homem - como prestígio e poder, são compreendidas como o principal fator de divisão entre os próprios homens. PereirA ${ }^{8}$ afirma que: "[...] o homem é intimidado pela imagem masculina que idealizou. Não é a mulher que exige dele o máximo, é o próprio homem” (p.97).

Cavaleiro e ViannA ${ }^{17}$ ressaltam:

Percebemos assim, a importância de fragilizar a consistência e o poder da masculinidade hegemônica como categoria social homogênea, explicitando formas com as quais meninos e garotos, nas aulas de Educação Física, são vítimas de sua suposta e real dominação (p.149).

\section{Turmas mistas e turmas femininas $\mathrm{x}$ turma masculina}

Traçando um paralelo desta pesquisa com os estudos sobre a exclusão em aulas mistas e turmas femininas de Educação Física, onde o grau de habilidade motora para a realização das tarefas foi o fator 
predominante de exclusão, não foram encontradas diferenças em relação a uma turma composta apenas por sujeitos do sexo masculino. Devide et al. ${ }^{6}$, concluíram em sua pesquisa com turmas femininas que grande parte das alunas apresenta dificuldades para lidar com as diferenças de habilidade, assim como os meninos, excluindo e recriminando erros das colegas de equipe, durante os jogos esportivos. A diferença principal da investigação em turmas femininas esteve relacionada à afetividade, que se fez presente nos resultados identificados pelos autores, minimizando o quadro de exclusão:

As anotações de campo indicam que quando há laços de amizade sólidos entre as alunas, há uma tendência à tolerância dos erros das colegas, ainda que a equipe seja heterogênea em relação à habilidade motora para o desporto. Isto demonstra que a homogeneidade quanto ao grau de habilidade motora e quanto à afetividade nas atividades são fatores determinantes para uma melhor interação social entre as participantes ${ }^{6}$ (p.99).

Para PereirA ${ }^{8}$ : "Os homens são educados para serem superiores: competitivos, ativos, agressivos, e independentes, racionais e intelectuais; enquanto as mulheres são educadas para serem emocionais e sentimentais [...]" (p.96). Relações de maior proximidade são mais permitidas às meninas, através de um comportamento socialmente legitimado, conforme constatado na pesquisa com turmas femininas de Educação Física. Louro ${ }^{41}$ corrobora com esta questão:

Usualmente também se observa que as formas de manifestação de afeto e de companheirismo entre as meninas e mulheres envolvem uma proximidade física e uma intimidade que não é tolerada para com os meninos e isso poderia ajudar a "afrouxar" a rigidez de fronteiras do comportamento permitido para o relacionamento entre elas. A vigilância para garantir a masculinidade dos meninos é então exercida mais intensamente desde os primeiros anos de vida, pela família e pela escola (p.54).

Apesar de ter havido um quadro mais humanístico, constatado pela presença da afetividade nas turmas femininas, este não se fez por completo, pois a cultura hegemônica do esporte e da competitividade ainda se fez valer, ao existir exclusões por habilidade motora também entre as meninas, conforme DEVIDE et al. ${ }^{6}$ constataram. A exclusão gerada pela competitividade nas aulas de Educação Física manifesta-se nos indivíduos independente do sexo ${ }^{38}$.

Os estudos sobre aulas de Educação Física mistas, como já citados, apontam os critérios de exclusão baseados também nas diferenças de desempenho motor dos/as alunos/as, embora esta exclusão por habilidade, não ocorra exclusivamente com o sexo feminino, segundo AltmanN ${ }^{38}$. Entretanto existe uma grande predominância desse tipo de exclusão nas pesquisas realizadas ${ }^{1-3}$.

A análise comparativa sobre os critérios de exclusão em turmas mistas, femininas e a turma masculina obteve como elemento similar o grau de habilidade motora para as práticas corporais. DEvide et al. ${ }^{6}$, discorrem sobre a questão da habilidade motora como fator de exclusão nas aulas de Educação Física escolar:

O grau de habilidade motora para o desporto tem sido o elemento central para a inclusão da minoria mais apta nas atividades do ponto de vista motor na EFe. Quando a habilidade motora torna-se o principal critério para os discentes se organizarem em grupos na EFe torna-se uma barreira, dificultando a troca de experiências intersexo e intrassexo [...] (p.102).

SANTOS $^{22}$ enaltece que ao lidar com a diversidade, os educadores devem sempre garantir aos discentes igualdade de oportunidades, além de: "ser capaz de reconhecer os talentos e as limitações dos educandos e planejar suas aulas de acordo.” (p.11). A Educação Física seja em turmas mistas, femininas ou masculinas, pode e deve internalizar este viés em sua prática pedagógica, reconhecendo às diferenças e à diversidade entre os sujeitos.

Como considerações finais, a categoria gênero, por muito tempo, não foi uma instância prioritária nas preocupaçôes pedagógicas de professores/as e nos planejamentos escolares das aulas de Educação Física, passando a ser reconhecida apenas quando se instituiu as aulas mistas da referida disciplina nas escolas, onde vantagens, desvantagens e desafios passaram a ser então identificados nas práticas corporais realizadas em conjunto por meninos e meninas. No caso desta pesquisa estivemos diante de conflitos existentes também em aulas separadas por sexo, neste caso em uma turma masculina, onde mecanismos de inclusão/ exclusão se fizeram presentes entre os meninos. A problematização das questões atuais de gênero, através do reconhecimento da existência de feminilidades e masculinidades entre alunos e alunas, mostra-se essencial e indispensável nas práticas pedagógicas que buscam a inclusão e uma participação efetiva de meninos e meninas nas aulas de Educação Física.

$\mathrm{O}$ modelo hegemônico de masculinidade fezse predominante entre os meninos nas aulas de Educação Física investigadas. A competitividade, como uma das características centrais desta forma dominante de masculinidade, mostrou-se como o 
principal mecanismo gerador dos processos de inclusão/exclusão durante as observações, permeada pela valorização do domínio das habilidades físicas e motoras dos mais aptos para a prática do Futebol. De forma secundária, masculinidades cúmplices e subordinadas estiveram presentes entre os meninos durante as aulas, sendo visivelmente dominadas pela sua forma hegemônica.

De qualquer forma é importante salientar que estes resultados ocorreram em um contexto específico. Distintas formas de masculinidades se sobressairão e estarão presentes de variadas maneiras, seja em turmas masculinas ou mesmo nas aulas mistas de Educação Física escolar, onde a prática pedagógica do(a) professor(a) e as interações entre os sujeitos, por meio dos esportes e das atividades corporais, podem permitir a inclusão e o convívio harmonioso das múltiplas masculinidades, pelo menos até que outras culturas, políticas e práticas se tensionem com as inclusivas, colocando estas em cheque novamente, no eterno movimento complexo e dialético que uma análise omnilética permite entrever.

\title{
Notas
}

a. Trata-se de uma construção conceitual que reúne as noções de dialética, complexidade e tridimensionalidade para compreender os processos de inclusão/exclusão, reconfigurando nossa compreensão a partir da tentativa de visualizar o que escape ao binarismo, a uma visão polarizada, e contemplar o que ainda não seja visível, o que ainda nos seja estranho, o que ainda não seja passível de imaginação em uma primeira mirada, mas que ali está como possibilidade. Pensar omniléticamente é pensar os processos de inclusão/exclusão de forma totalizante e complexa.

b. Considerado um conceito complexo e controverso, o patriarcado pode ser definido, de forma resumida, como a subordinação feminina e a necessidade dos homens de dominarem as mulheres ${ }^{29}$.

c. Ressalto que as aulas de Educação Física na rede municipal de educação de Nova Iguaçu são mistas. No caso específico desta escola, a professora opta pela separação entre turmas masculinas e femininas, como opção metodológica, obtendo o consentimento da direção.

d. Conforme relatado anteriormente, os nomes atribuídos aos alunos são fictícios, preservando assim o anonimato dos participantes da pesquisa.

\begin{abstract}
Masculinities in school Physical Education: a study on the processes of inclusion/exclusion

This case study aimed to identify the processes of inclusion/exclusion, in a class of elementary school physical education. Inclusion/exclusion, in this work, are understood in a relationship dialectic, a phenomenon understood under a dynamic characteristic and inseparable, where one cannot consider them through distinct meanings. We found through participant observation, with annotations in field journal, that the central mechanism of inclusion/exclusion was based on physical performance and engine for the practice of sports, together with a competitiveness exacerbated, central feature of hegemonic model of masculinity which was predominant among the boys in class. We recognize that the pedagogical practice of the teacher can influence the interactions between subjects during body activities, allowing the harmonious coexistence of multiple forms of masculinity among students, toward the movement for inclusion in physical education classes and in education in general.
\end{abstract}

KEY WORDS: Gender; Education; Sport. 


\section{Referências}

1. Abreu NG. Análise das percepções de docentes e discentes sobre turmas mistas e separadas por sexo nas aulas de educação física escolar. In: Romero E, organizador. Corpo, mulher e sociedade. Campinas: Papirus; 1995. p. 157-76.

2. Daolio J. A construção cultural do corpo feminino ou o risco de transformar meninas em "antas". In: Romero E, organizador. Corpo, mulher e sociedade. Campinas: Papirus; 1995. p. 99-108.

3. Andrade EB. As representações sociais de alunas sobre sua auto exclusão nas aulas de educação física no ensino médio. $9^{\circ}$ Encontro Fluminense de Educação Física Escolar; Niterói, BR. Niterói: DEFD/UFF; 2005. p. 102-5.

4. Vieira JJ. "Jogo de mulher e jogo pra valer": revisitando as representaçôes sociais discentes sobre uma velha dicotomia. In: Romero E, Pereira EGB, organizadores. Universo do corpo: masculinidades e feminilidades. Rio de Janeiro: Shape; 2008. p. 255-66.

5. Casco P. Mais e melhores práticas para inclusão de meninas na Educação Física escolar. In: Knijnik JD, Zuzzi RP, organizadores. Meninas e meninos na educação física: gênero e corporeidade no século XXI. Jundiaí: Fontoura; 2010. p.73-85.

6. Devide FP, Lima FR, Batista RS, Rodrigues, FSJ. Exclusão intrassexo em turmas femininas na educação física escolar: quando a diferença ultrapassa a questão de gênero. In: Knijnik JD, Zuzzi RP, organizadores. Meninas e meninos na educação física: gênero e corporeidade no século XXI. Jundiaí: Fontoura; 2010. p. 87-105.

7. Knijnik JD, Machado AA. Bailarinos do esporte: notas sobre novas masculinidades em campo. In: Romero E, Pereira EGB, organizadores. Universo do corpo: masculinidades e feminilidades. Rio de Janeiro: Shape; 2008. p. 137-1.

8. Pereira EGB. Discutindo gênero, corpo e masculinidade. In: Romero E, Pereira EGB, organizadores. Universo do corpo: masculinidades e feminilidades. Rio de Janeiro: Shape; 2008. p. 87-101.

9. Pereira EGB, Fernandes Filho J. Masculinidade na educação física: uma breve discussão. Rev Irundú. 2008;1:97-110.

10. Pereira EGB. Reflexôes sobre práticas corporais, identidades e masculinidades. Rev Bras Psicol Esporte Motricidade Hum. 2009;1:37-43.

11. Devide FP, Batista RS. O exercício físico na construção da identidade de gênero: por uma masculinidade plural. In: Knijnik JD, organizador. Gênero e esporte: masculinidades e feminilidades. Rio de Janeiro: Apicuri; 2010. p. 185-209.

12. Knijnik JD, Falcão-Defino PC. Esporte e masculinidades: uma longa história de amor, ou melhor, de amizade. In: Knijnik JD, organizador. Gênero e esporte: masculinidades e feminilidades. Rio de Janeiro: Apicuri; 2010. p. 161-83.

13. Melo VA, Lacerda C. Masculinidades e dança, masculinidades e esporte: relações. In: Knijnik JD, organizador. Gênero e esporte: masculinidades e feminilidades. Rio de Janeiro: Apicuri; 2010. p. 111-36.

14. Silva P, Gomes PB, Goellner SV. Educação física no sistema educativo português: um espaço de reafirmação da masculinidade hegemónica. Rev Bras Educ Fís Esporte. 2008;22:219-33.

15. Pereira EGB, Fernandes Filho J. A construção das masculinidades: os discursos e as imagens na educação física infantil. Rev InterSciencePlace. 2009;2. Disponível em: http://www.interscienceplace.org/interscienceplace/article/view/87/91.

16. Pereira EGB. O masculino na educação física infantil: discursos e imagens. Rev Bras Psicol Esporte Motricidade Hum. 2010;2:74-8.

17. Cavaleiro MC, Vianna C. Chutar é preciso? Masculinidades e educação física escolar. In: Knijnik JD, Zuzzi RP, organizadores. Meninas e meninos na educação física: gênero e corporeidade no século XXI. Jundiaí: Fontoura; 2010. p. 137-54.

18. Moraes e Silva M, César MRA. Mapeamentos e cartografias: percepçôes de professores (as) sobre as masculinidades produzidas nas aulas de Educação Física. In: Knijnik JD, Zuzzi RP, organizadores. Meninas e meninos na educação física: gênero e corporeidade no século XXI. Jundiaí: Fontoura; 2010. p. 155-74.

19. Brito LT. Masculinidades e educação física escolar: interlocuções. Lect Educ Fís Deportes. 2011;161. Disponivel em: http://www.efdeportes.com/efd161/masculinidades-e-educacao-fisica-escolar.htm.

20. Moraes e Silva M, César MRA. As masculinidades produzidas nas aulas de educação física: percepções docentes. Motrivivência. 2012;24:101-12.

21. Santos MP, Paulino MM. Inclusão em educação: uma visão geral. In: Santos MP, Paulino MM, organizadores. Inclusão em educação: culturas, políticas e práticas. São Paulo: Cortez; 2006. p. 11-5.

22. Santos MP. Inclusão. In: Santos MP, Fonseca MPS, Melo SC, organizadores. Inclusão em educação: diferentes interfaces. Curitiba: CRV; 2009. p. 9-21.

23. Booth T, Ainscow M. Index para a inclusão: desenvolvendo a aprendizagem e a participação na escola. Tradução deMônica Pereira dos Santos. Rio de Janeiro: LaPEADE; 2002.

24. Fonseca MPS, Santos MP, Venturini AM. Concepções sobre inclusão e exclusão: licenciandos de educação física em foco. VI Congresso Brasileiro Multidisciplinar de Educação Especial; VII Encontro da Associação Brasileira de Pesquisadores em Educação Especial; Londrina, BR. Londrina: CBMEE; 2011. p. 98-109. 
25. Konder L. O que é dialética. 28a ed. São Paulo: Brasiliense; 2008.

26. Morin E. Introdução ao pensamento complexo. 4a ed. Porto Alegre: Sulina; 2011.

27. Bordieu P. A dominação masculina. 6a ed. Rio de Janeiro: Bertrand Brasil; 2009.

28. Silva TT. Documentos de identidade: uma introdução às teorias do currículo. 2a ed. Belo Horizonte: Autêntica; 2007.

29. Scott J. Gênero: uma categoria útil de análise histórica. Educ Realidade. 1995;20:71-99.

30. Connell RW. Políticas da masculinidade. Educ Realidade. 1995;20:185-206.

31. Connell RW. Masculinidades. México: UNAM/PUEG; 2003.

32. Dunning E. O desporto como área masculina reservada: notas sobre os fundamentos sociais da identidade masculina e as suas transformações. In: Norbert E, organizador. A busca da excitação. Lisboa: Diefel; 1992. p. 389-412.

33. Oliveira PP. A construção social da masculinidade. Belo Horizonte: UFMG; 2004.

34. Paechter C. Meninos e meninas: aprendendo sobre masculinidades e feminidades. Porto Alegre: Artmed; 2009.

35. Yin RK. Estudo de caso: planejamento e métodos. 4a ed. Porto Alegre: Bookman; 2010.

36. Oliveira MM. Como fazer pesquisa qualitativa. 2a ed. Petrópolis: Vozes; 2008.

37. Bardin L. Análise de conteúdo. São Paulo: Edições 70; 2011.

38. Altmann H. Rompendo fronteiras de gênero: Marias (e) homens na educação física [dissertação]. Belo Horizonte(MG): Universidade Federal de Minas Gerais, Faculdade de Educação; 1998.

39. Louro GL. Gênero, sexualidade e educação: uma perspectiva pós-estruturalista. 10a ed. Petrópolis: Vozes; 2008.

40. Silva AP. O professor de educação física como agente do processo inclusivo. In: Santos MP, Paulino MM, organizadores. Inclusão em educação: culturas, políticas e práticas. São Paulo: Cortez; 2006. p. 69-81.

41. Louro GL. Currículo, gênero e sexualidade. Porto: Porto; 2000.

\begin{tabular}{|c|c|}
\hline $\begin{array}{r}\text { ENDEREÇO } \\
\text { Leandro Teofilo Brito } \\
\text { Faculdade de Educação } \\
\text { Universidade Federal do Rio de Janeiro } \\
\text { Av. Pasteur, 250 funtos - 20. andar - Campus Praia Vermelha } \\
22290-240 \text { - Rio de Janeiro - RJ - BRASIL } \\
\text { e-mail: teofilo.leandro@gmail.com }\end{array}$ & $\begin{array}{l}\text { Recebido para publicação: 15/09/2012 } \\
\text { Revisado: 03/03/2013 } \\
\text { Aceito: 05/03/2013 }\end{array}$ \\
\hline
\end{tabular}

